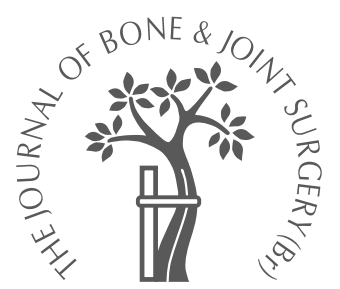

P. Harvie,

S. J. Ostlere,

J. Teh,

E. G. McNally,

K. Clipsham,

B. J. Burston,

T. C. B. Pollard,

A. J. Carr

From the University

of Oxford, England

P. Harvie, MRCS,

Girdlestone Memorial

Scholar in Orthopaedic

Surgery

S. J. Ostlere, FRCR,

Consultant Radiologist

J. Teh, FRCR, Consultant

Radiologist

E. G. McNally, FRCR,

Consultant Radiologist

K. Clipsham, RGN,

Research Nurse

B. J. Burston, MB ChB

Basic Surgical Trainee,

Oxford Region

T. C. B. Pollard, MB ChB

Basic Surgical Trainee,

Oxford Region

A. J. Carr, FRCS, Nuffield

Professor of Orthopaedic

Surgery

Nuffield Department of

Orthopaedic Surgery,

University of Oxford,

Nuffield Orthopaedic Centre,

Windmill Road, Headington,

Oxford OX3 7LD, UK.

Correspondence should be sent to Professor A. J. Carr.

(C)2004 British Editorial

Society of Bone and

Joint Surgery

doi:10.1302/0301-620X.86B5.

$14747 \$ 2.00$

$J$ Bone Joint Surg [Br]

2004;86-B:696-700.

Received 7 January 2003;

Accepted after revision

1 October 2003

\title{
Genetic influences in the aetiology of tears of the rotator cuff
}

\author{
SIBLING RISK OF A FULL-THICKNESS TEAR
}

\author{
From a retrospective, cohort study of $\mathbf{2 0 5}$ patients diagnosed with full-thickness tears of \\ the rotator cuff, we determined, using ultrasound, the prevalence of such tears in their 129 \\ siblings. Using 150 spouses as controls, the relative risk of full-thickness tears in siblings \\ versus controls was $2.42(95 \% \mathrm{Cl} 1.77$ to 3.31$)$. The relative risk of symptomatic full- \\ thickness tears in siblings versus controls was 4.65 (95\% $\mathrm{Cl} 2.42$ to 8.63$)$. \\ The significantly increased risk for tears in siblings implies that genetic factors play a \\ major role in the development of full-thickness tears of the rotator cuff.
}

In the UK the shoulder is the third commonest site of musculoskeletal disease $(16 \%)$ after the spine and knee $(23 \% \text { and } 19 \% \text {, respectively })^{1}$ as well as being the third most common reason for orthopaedic referral in the USA $(7.9 \%)$ after the knee and spine $(14.9 \%$ and $8.2 \%$, respectively). ${ }^{2}$ Full-thickness tears of the rotator cuff are among the most frequently encountered causes of pain and dysfunction in the shoulder. $^{3}$

Estimates for the prevalence of full-thickness tears vary widely. Most cadaver studies give a prevalence of $20 \%,{ }^{4}$ but estimates of $5 \%$ to $30 \%{ }^{5,6}$ have been published. In asymptomatic individuals estimates of prevalence of $15 \%$ to $23.4 \%$ have been described after investigation by $\mathrm{MRI}^{7}$ and ultrasound. ${ }^{8}$ All studies agree that the prevalence increases with age and that its associated morbidity, in terms of pain and loss of function, can be severely debilitating. Pain in the shoulder is a common cause of absenteeism from work and is a burden on medical resources. ${ }^{9}$ Reported estimates for the mean cost of repair of a rotator cuff vary from US\$ $9444^{10}$ to US\$ $25870^{11}$ with a mean time off work of seven months.

Theories regarding the causes of full-thickness tears are varied. Historically, mechanical compression of the tendons of the cuff was thought to be the initiating factor. Acromial morphology and the presence of spurs, the morphology of the coracohumeral ligament and the presence of osteophytes at the acromioclavicular joint were all considered to be relevant, although, as early as 1934 , Codman ${ }^{12}$ favoured an intrinsic theory of degeneration of the tendons of the cuff. Current opinion favours a combination of repetitive microtrauma in association with age-related degenerative changes within the tendons. There is a lack of understanding as to what causes pain in a full-thickness tear and why symptoms are so variable.

Increasingly, such tears are being regarded as a normal consequence of the ageing process. ${ }^{8,13}$ No studies to date have addressed a possible genetic basis for their pathogenesis and symptomatology. We therefore describe the results of a prospective, cross-sectional study of patients with full-thickness tears. Our aim was to establish the relative risk of their development as well as the risk of occurrence of symptomatic tears in siblings of patients with tears which had been diagnosed by ultrasound.

\section{Patients and Methods}

Computerised hospital records were used to identify all patients who had been diagnosed with full-thickness tears of the rotator cuff by ultrasound between August 1996 and January 2002 at our institution. All the patients were invited to complete and return a short postal questionnaire. The enquiry focused on the age, ethnic origin, marital status and the number of first-degree siblings of each patient as well as any previous history of known pathology of the shoulder among their spouse or siblings. Patients were excluded from the study if they had no living spouse or siblings, were not available for review or had previously undergone arthroplasty of the shoulder. In order to limit confounding from racial variation, nonCaucasian patients were also excluded. From a 
Table I. Participants excluded from the study

\begin{tabular}{llr}
\hline Group & Reason & Number \\
\hline Probands & No spouse or siblings & 65 \\
& Not available for study & \\
$\quad$ Patient death & 18 \\
$\quad$ Initial questionnaire not returned & 192 \\
$\quad$ Later refusal to participate & 75 \\
$\quad$ Unwell & 20 \\
& Previous shoulder arthroplasty & 6 \\
& Non-Caucasian patients & 6 \\
Siblings & Not available for study & \\
$\quad$ Sibling death & 133 \\
& Refusal & 74 \\
$\quad$ Unwell & 45 \\
& Location unknown by patient & 64 \\
$\quad$ Outside region & 321 \\
& Not full first-degree relative to patient & \\
By marriage & 18 \\
$\quad$ By adoption & 6 \\
& Systemic disease affecting shoulder function & \\
$\quad$ Polymyalgia rheumatica & 4 \\
$\quad$ Rheumatoid arthritis & 4 \\
Hemiparesis & 2 \\
\hline
\end{tabular}

consecutive series of 595 patients with full-thickness tears 382 were excluded. Each was sent an information sheet and contacted by telephone. Details of spouse and siblings were obtained and each of these was sent an information sheet and also contacted by telephone. Siblings were excluded if they were not available for review, were not full first-degree relatives of the patient, either by marriage or adoption, or had concomitant systemic disease affecting the function of the shoulder. Of 810 siblings identified 671 were excluded. All participant exclusions are listed in Table I.

Between February 2002 and February 2003, 213 patients, 150 spouses and 129 siblings attended for review. Recruitment to the study and assessments and reviews were undertaken by a single researcher $(\mathrm{PH})$. All participants completed the SF-36 health survey questionnaire ${ }^{14}$ in addition to the Oxford shoulder score ${ }^{15}$ (OSS) and the score of Constant and Murley ${ }^{16}$ (CMS) for each shoulder. A Nottingham Mecmesin Myometer (Atlantech Medical Devices Ltd, Harrogate, UK) was used to measure strength for the CMS. Both the SF-36 and OSS were completed by the patient independently and later reviewed with the researcher. Each participant, with fully informed consent (Oxford Regional Ethics Committee Ref. No. C01.277), subsequently underwent ultrasound of both shoulders carried out by a consultant musculoskeletal radiologist (JT, EM or SO) using a Philips Ultrasound HD1-5000 scanner with a 5 to $12 \mathrm{MHz}$ variable frequency linear-array probe (Philips Ultrasound, Letchworth, UK). The radiologist was not aware of the status of the participant and reported all scans using a standardised proforma. All full-thickness tears detected were classified according to the criteria of Post, Silver and Singh ${ }^{17}$ using the size of the largest meas- ured tear. Partial-thickness tears were not included. Patients were rescanned to confirm the presence of a full-thickness tear and to validate their identification as index cases and thus justify the inclusion of their spouse and/or siblings in the study. Of 213 patients scanned, eight were found to have no lesion and were subsequently excluded from the study, with eight associated spouses and ten siblings. The defined end-point was the identification of siblings and spouses with a full-thickness tear, whether unilateral or bilateral. Unilateral or bilateral tears carried equal weighting for relative risk calculations. Unless stated, all the results were calculated and tabulated in terms of the number of participants with or without full-thickness tears and not in terms of the number of shoulders examined within each cohort. Symptomatic tears in siblings and spouses were defined by a subjective patient statement in addition to an OSS $\geq 13$. The relative risk of development of a lesion in siblings was derived both overall and for symptomatic tears and stratified according to age.

Relative risk to siblings $(\lambda s)$. Risk estimates based on the presence of full-thickness tears in siblings and spouses were obtained using the following equation:

$$
\lambda \mathrm{s}=\frac{\% \text { siblings with full-thickness tears }}{\% \text { spouses with full-thickness tears }}
$$

The result is given as a ratio with $95 \%$ confidence intervals (CI). ${ }^{18}$

Outcome measures. For the purposes of this study outcome measures specific for the shoulder (CMS and OSS), were applied to both siblings and spouses in order to identify symptomatic participants and to compare variations in symptomatology in both cohorts. This was used as a means of assessing the degree of homogeneity of symptoms between both groups and not for the evaluation of function or outcome after treatment. Similarly, the SF-36 questionnaire was applied to both cohorts in order to assess the degree of homogeneity in general health status between them and not for evaluation after treatment.

The Constant Murley shoulder score (CMS). This is a shoulder-specific, non-condition-specific, combined clinician/ patient-based scoring system. It is scored from 0 to 100 with low scores denoting poor function and pain. It allocates 15 and 20 points, respectively, for the subjective assessment of pain and the activities of daily living, as well as 40 and 25 points, respectively, for the active range of movement and power.

The Oxford Shoulder Score (OSS). This is a shoulder-specific, non-condition-specific, patient-based scoring system. It is scored from 12 to 60, with 12 the best; and 60 the worst, and assesses pain and activities of daily living. It is consisent, reproducible, valid and sensitive to clinical changes at six months after surgery. ${ }^{19}$

SF-36. This is a 36 -item questionnaire which is widely used to assess general health. It assesses eight dimensions: physical function, social function, role limitation due to physical problems, role limitation due to mental problems, mental 
Table II. Age distribution of probands, siblings and spouses with and without fullthickness tears

\begin{tabular}{lllll}
\hline & & \multicolumn{4}{l}{ Mean age in years (range) } \\
\cline { 3 - 5 } & Number & All & With full-thickness tear & No tear \\
\hline Probands & 205 & $64.0(36$ to 86$)$ & $64.0(36$ to 86$)$ & N/A \\
Siblings & 129 & $63.1(41$ to 85$)$ & $65.1(41$ to 85$)$ & 60.1 (41 to 77) \\
Spouses & 150 & $62.4(43$ to 85$)$ & $66.2(53$ to 85$)$ & 60.1 (43 to 81) \\
\hline
\end{tabular}

Table III. Gender distribution of probands, siblings and spouses with and without full-thickness tears

\begin{tabular}{|c|c|c|c|c|}
\hline & \multirow[b]{2}{*}{ Number } & \multicolumn{3}{|c|}{ Male:female (male \%) } \\
\hline & & All & With full-thickness tear & No tear \\
\hline Probands & 205 & $115: 90$ (56) & $115: 90(56)$ & N/A \\
\hline Siblings & 129 & $64: 65$ (50) & $40: 37 \quad(52)$ & $24: 28$ (46) \\
\hline Spouses & 150 & $72: 78$ (48) & $19: 18$ (51) & $53: 60 \quad(47)$ \\
\hline
\end{tabular}

Table IV. Distribution of the sizes of tear in all lesions found in 129 siblings and 150 spouses

\begin{tabular}{lrcrc}
\hline Tear size & \multicolumn{2}{c}{ Siblings (\% of total tears) } & \multicolumn{2}{c}{ Spouses (\% of total tears) } \\
\hline Small & 58 & $(49.2)$ & 30 & $(51.8)$ \\
Medium & 39 & $(33.1)$ & 19 & $(32.8)$ \\
Large & 9 & $(7.6)$ & 3 & $(5.2)$ \\
Massive & 12 & $(10.1)$ & 6 & $(10.2)$ \\
Total $(\%)$ & 118 & $(100)$ & 58 & $(100)$ \\
\hline
\end{tabular}

Table V. Variation of the presence of full-thickness tears with hand dominance for unilateral tears and the size of the largest tear and hand dominance for bilateral tears in probands, siblings and spouses

\begin{tabular}{|c|c|c|c|c|}
\hline Group & Uni-bilaterality (\%) & Dominant (\%) & Non-dominant (\%) & Same (\%) \\
\hline \multirow[t]{2}{*}{ Probands } & 57 unilateral (27.8) & $40 \quad(70.2)$ & 17 (29.8) & N/A \\
\hline & 148 bilateral (72.7) & $44 \quad(29.7)$ & $18 \quad(12.2)$ & $86 \quad(58.1)$ \\
\hline \multirow[t]{2}{*}{ Siblings } & 36 unilateral (46.8) & $24 \quad(66.7)$ & 12 (33.3) & $\mathrm{N} / \mathrm{A}$ \\
\hline & 41 bilateral (53.2) & 17 (41.4) & $2 \quad(4.9)$ & (53.7) \\
\hline \multirow[t]{2}{*}{ Spouses } & 16 unilateral (43.2) & 11 (68.8) & $5 \quad(31.2)$ & $\mathrm{N} / \mathrm{A}$ \\
\hline & 21 bilateral (56.8) & 6 (28.5) & 1 (4.8) & 14 (66.7) \\
\hline
\end{tabular}

health, energy/vitality, pain and general health perception, giving a summary of both physical and mental components.

It is widely recognised that variations in the power component of the CMS and all dimensions of the SF-36 occur with age and gender. ${ }^{20}$ These do not necessarily represent abnormal function of the shoulder or poor health. Because the siblings and spouses were closely matched in terms of age and gender, the two scores were not normalised. Significance tests were performed using the chi-squared test to compare proportions in the two groups, with Yates's correction for the small sample size.

\section{Results}

Tables II and III show the age and gender distribution of probands, siblings and spouses, respectively, in those with and without full-thickness tears. The distribution of the size of the tears found in each cohort is given in Table IV and the proportion of unilateral and bilateral tears found in each group, the variation in the presence of unilateral tears with hand dominance, and how the size of the largest tear in individuals with bilateral tears varies with hand dominance in Table V. Table VI shows the variation in age of siblings and spouses found to have full-thickness tears and Tables VII and VIII show age-stratified relative risk estimates for the development of full-thickness tears both overall and in those with symptoms, respectively.

Relative to a control group, siblings had more than twice the risk of developing such tears $(\mathrm{p}<0.0001)$ and nearly five times the risk of suffering symptoms $(\mathrm{p}<0.0001)$. The prevalence of these lesions in young controls is low, as is the presence of symptomatic tears in controls of all ages.

No significant differences $(\mathrm{p}>0.05)$ were found in all other measures of comparison between siblings and spouses both with and without tears. 
Table VI. Proportion of siblings and spouses with full-thickness tears and variation with age. The percentage of individuals with full-thickness tears in each age range for both cohorts is shown in parentheses

\begin{tabular}{|c|c|c|c|c|c|c|}
\hline \multirow{3}{*}{$\frac{\text { Group }}{\text { Siblings }}$} & \multicolumn{6}{|c|}{ Age range (yrs) } \\
\hline & \multirow{2}{*}{$\begin{array}{l}\mathbf{4 0} \text { to } \mathbf{4 9} \\
5 / 14 \quad(6.5)\end{array}$} & \multirow{2}{*}{$\begin{array}{l}\mathbf{5 0} \text { to } 59 \\
19 / 35(24.7)\end{array}$} & \multirow{2}{*}{$\begin{array}{l}60 \text { to } 69 \\
26 / 41 \quad(33.8)\end{array}$} & \multirow{2}{*}{$\begin{array}{l}70 \text { to } 79 \\
24 / 36(31.2)\end{array}$} & \multicolumn{2}{|c|}{80 to 89} \\
\hline & & & & & $3 / 3$ & (3.8) \\
\hline Spouses & $0 / 15 \quad(0)$ & $8 / 47$ (21.6) & 17/53 (45.9) & $10 / 30(27.0)$ & $2 / 5$ & (5.5) \\
\hline
\end{tabular}

Table VII. Age-stratified and overall relative risk estimates, with $95 \% \mathrm{Cl}$ intervals and corresponding $p$ values for full-thickness tears in siblings compared with spouses of patients with such lesions

\begin{tabular}{lcclll}
\hline & \multicolumn{2}{l}{ Prevalence } & & & \\
\cline { 2 - 3 } Age range (yrs) & Sibling & Spouse & & Relative risk & p value \\
\hline 80 to 89 & $3 / 3$ & $2 / 5$ & $2.50(0.85$ to 7.31$)$ & 0.0897 \\
70 to 79 & $24 / 36$ & $10 / 30$ & $2.00(1.15$ to 3.49$)$ & 0.0070 \\
60 to 69 & $26 / 41$ & $17 / 53$ & $1.98(1.25$ to 3.12$)$ & 0.0025 \\
50 to 59 & $19 / 35$ & $8 / 47$ & $3.19(1.58$ to 6.43$)$ & 0.0004 \\
40 to 49 & $5 / 14$ & $0 / 15$ & & N/A & N/A \\
Overall & $77 / 129$ & $37 / 150$ & $2.42(1.77$ to 3.31$)$ & $<0.0001$ \\
\hline
\end{tabular}

Table VIII. Age-stratified and overall relative risk estimates, with $95 \% \mathrm{Cl}$ and corresponding $\mathrm{p}$ values for siblings with symptomatic full-thickness tears compared with symptomatic spouses of patients with such lesions

\begin{tabular}{lcclll}
\hline & \multicolumn{2}{l}{ Prevalence } & & & \\
\cline { 2 - 3 } Age range (yrs) & Sibling & Spouse & Relative risk & p value \\
\hline 80 to 89 & $3 / 3$ & $0 / 5$ & & N/A & N/A \\
70 to 79 & $10 / 36$ & $1 / 30$ & $8.33(1.13$ to 61.40$)$ & 0.0068 \\
60 to 69 & $14 / 41$ & $6 / 53$ & $3.02(1.27$ to 7.16$)$ & 0.0073 \\
50 to 59 & $9 / 35$ & $3 / 47$ & $4.03(1.18$ to 13.80$)$ & 0.0143 \\
40 to 49 & $4 / 14$ & $0 / 15$ & & N/A & N/A \\
Overall & $40 / 129$ & $10 / 150$ & $4.65(2.42$ to 8.93$)$ & $<0.0001$
\end{tabular}

\section{Discussion}

No previous studies have considered the role of genetic factors in the development of full-thickness tears of the rotator cuff. Controls used for estimation of risk. Estimates of the risk to family members depend on the choice of controls. To determine genetic factors in a presumed multifactorial disease, controls used in sibling studies should ideally resemble their siblings with respect to environmental risk factors but differ in regard to possible genetic determinants. Spouses of patients fulfil both these criteria and have been used previously in family studies. ${ }^{21-23}$ By their longstanding proximity to the patient, spouses and siblings share a common environment and similar positive and negative biases to the development of full-thickness tears. Clearly, this shared environment is limited. The siblings experience the same environment during childhood and the spouse during adult years. Nevertheless, this is the best environmental matching that can reasonably be achieved.

Possible errors. Variation in the balance of known environmental and constitutional risk factors such as age, gender and occupation can affect relative risk estimates. In our study both the siblings and spouses were very closely matched in terms of age and gender (Tables II and III). Details of their occupation were obtained from all participants in this study. Although there are no standard data which associate occupation with the risk of the development of full-thickness tears attempts were made to categorise occupation according to the degree of manual labour, overhead activity and repetitive movements of the upper limb involved. Overall, no significant variations were seen between siblings and spouses and both groups were found to have excellent association in terms of general health status and the level of symptoms in the shoulder.

Another source of error is an ascertainment bias. The end-point for each participant in this study was the identification of the presence or absence of a full-thickness tear by ultrasound. The radiologists were aware of the nature of this study and thus had a theoretical risk of overdiagnosing the existence of tears. In order to minimise this, the radiologists were not told the status of the participants. The three radiologists who performed the ultrasonography were consultant musculoskeletal radiologists at a specialist orthopaedic hospital, who were highly experienced in these techniques, and scanned both siblings and controls. 
All participants were recruited on the basis of being firstdegree relatives of probands and not because they had symptoms. It was likely, however, that siblings and spouses with symptomatic shoulders would be more likely to participate in such a study than if they had no complaints. This self-selection bias could significantly affect relative risk calculations if confined to a single cohort, but both groups were equally liable to such self-selection and therefore the calculations of overall relative risks were not affected significantly.

Our study shows that there is significant genetic susceptibility towards the development of full-thickness tears of the rotator cuff and associated symptoms. Siblings had more than twice the relative risk for developing a lesion and nearly five times the risk of experiencing symptoms. This implies that there is an important role for genetic factors in a disease traditionally thought to reflect age-related 'wear and tear'. Environmental factors do contribute to the aetiology but our study indicates that genetic influences also have a role. The phenotypic expression of any genetic susceptibility to the development of a full-thickness tear is likely to occur at the level of the ultrastructure of the tendon in the cuff. A genetic basis for associated pain could theoretically be expressed at any point in the sensorineural pathway of the cuffs. The familial tendencies which we describe emphasise the need for further research into the anatomy, physiology and molecular biology of the ultrastructure of the tendon of the cuff.

Mr P. Harvie was funded by the Girdlestone Memorial Scholarship in Orthopaedic Surgery from The Lord Nuffield Orthopaedic Centre Trust.

No benefits in any form have been received or will be received from a commercial party related directly or indirectly to the subject of this article.

\section{References}

1. Urwin $\mathbf{M}$, Deborah $\mathbf{S}$, Allison $\mathbf{T}$, et al. Estimating the burden of musculoskeletal disorders in the community: the comparative prevalence of symptoms at different anatomical sites, and the relation to social deprivation. Ann Rheum Dis 1998:57: $649-55$
2. Schappert SM. Office visits to orthopaedic surgeons: United States, 1995-96. Adv Data 1998;302:1-32.

3. Bunker T. Rotator cuff disease. Curr Orthop 2002;16:223-33

4. Bunker TD, Schranz PJ. Clinical challenges in orthopaedics: the shoulder. First ed. Oxford: Isis Medical Media Ltd, 1998.

5. Neer CS 2nd, Saterlee CC, Dalsey RM, Flatlow EL. The anatomy and potential affects of contracture of the coracohumeral ligament. Clin Orthop 1992;280:182-5.

6. Lehman C, Cuomo F, Kummer FJ, Zuckermann JD. The incidence of full thickness rotator cuff tears in a large cadaveric population. Bull Hosp Jt Dis 1995;54:30-1.

7. Sher JS, Uribe JW, Posada A, Murphy BJ, Zlatkin MB. Abnormal findings on magnetic resonance images of asymptomatic shoulders. J Bone Joint Surg [Am] 1995;77-A:10-5.

8. Tempelhof S, Rupp S, Seil R. Age-related prevalence of rotator cuff tears in asymptomatic shoulders. J Shoulder Elbow Surg 1999:8:296-9.

9. Bongers PM. The cost of shoulder pain at work. Br Med J 2001;322:64-5

10. Milne JC, Gartsman GM. Cost of shoulder surgery. J Shoulder Elbow Surg 1994;3:295-8.

11. Savoie FH 3rd, Field LD, Jenkins RN. Costs analysis of successful rotator cuff repair surgery: an outcome study: comparison of gatekeeper system in surgical patients. Arthroscopy 1995;11:672-6.

12. Codman EA. The shoulder: rupture of the supraspinatus tendon and other lesions in or about the subacrominal bursa. 1st ed. Boston: Thomas Todd, 1934.

13. Milgrom C, Schaffler M, Gilbert S, van Holsbeeck M. Rotator-cuff changes in asymptomatic adults: the effect of age, hand dominance and gender. J Bone Joint Surg [Br] 1995;77-B:296-8.

14. Ware JE, Sherbourne CD. The MOS 36-Item Short-Form Health Survey (SDF-36):1: conceptual framework and item selection. Med Care 1992;30:473-83.

15. Dawson J, Fitzpatrick R, Carr A. Questionnaire on the perceptions of patients about shoulder surgery. J Bone Joint Surg [Br] 1996;78-B:593-600.

16. Constant CR, Murley AHG. A clinical method of functional assessment of the shoulder. Clin Orthop 1987;214:160-4.

17. Post M, Silver R, Singh M. Rotator cuff tear: diagnosis and treatment. Clin Orthop 1983;173:78-91.

18. Katz D, Baptista J, Azen SP, Pike MC. Obtaining confidence intervals for the risk ratio in cohort studies. Biometrics 1978;34:469-74.

19. Dawson J, Hill G, Fitzpatrick R, Carr A. The benefits of using patient-based methods of assessment: medium-term results of an observational study of shoulder surgery. J Bone Joint Surg [Br] 2001;83-B:877-82.

20. Conboy VB, Morris RW, Kiss J, Carr AJ. An evaluation of the Constant-Murley shoulder assessment. J Bone Joint Surg [Br] 1996;78-B:229-32

21. Chitnavis J, Sinsheimer JS, Clipsham K, et al. Genetic influences in end stage osteoarthritis: sibling risk of hip and knee replacement for idiopathic osteoarthritis. J Bone Joint Surg [Br] 1997;79-B:660-4.

22. Lindberg H. Prevalence of primary coxarthrosis in siblings of patients with primary coxarthrosis. Clin Orthop 1986:203:273-55

23. Harburg E, Schull WJ, Erfurt JC, Schork MA. A family-set method for estimating hereditary and stress-1: a pilot survey of blood pressure among negroes in high and low stress areas, Detroit, 1966-1967. J Chronic Dis 1970;23:69-81. 